\title{
Testicular Damage after Exposure to Carbendazim Depends on the Number of Patent Efferent Ductules
}

\author{
Yukitoshi GOTOH, Jun NETSU ${ }^{1)}$, Masaaki NAKAI* and Tetsuo NASU \\ Department of Veterinary Anatomy, Faculty of Agriculture, Miyazaki University, Miyazaki 889-2192, and "Animal Health Business, \\ Pfizer Pharmaceuticals Inc., 2-1-1 Nishi-Shinjuku, Shinjuku-ku, Tokyo 163-0461, Japan
}

(Received 28 January 1999/Accepted 8 March 1999)

ABSTRACT. To study how long-term testicular damage depends on the patency of the efferent ductules (EFDs), rat testes and epididymides were examined after a single exposure to carbendazim (methyl 2-benzimidazole carbamate; MBC). The number of patent EFDs was determined in sections of the caput epididymides at 8, 16, 32 and 70 days post-treatment, and the testes were grouped into the following categories: those with intact EFDs, those with partially patent EFDs, or those with totally occluded EFDs. In each testis, 100 seminiferous tubules were examined for the presence of abnormalities. The mean weight of testes with partially patent EFDs was significantly higher compared with the control, whereas that of testes with totally occluded EFDs was significantly lower. Histologically, most seminiferous tubules of the testes with intact EFDs were normal. The testes with partially patent EFDs contained normal, degenerative and atrophic seminiferous tubules at various frequencies depending on the number of patent EFDs, and it was evident that as the number of patent EFDs increased, the number of normal seminiferous tubules also increased at any interval. In these testes, the number of normal seminiferous tubules increased progressively as the post-treatment interval increased, irrespective of patency of the EFDs. In the testes with totally occluded EFDs, atrophic seminiferous tubules were the most numerous. These results indicate that whether or not the testis is able to survive the long-term deleterious effects of MBC depends largely EFD patency.—KEY wORDs: carbendazim, efferent ductule, patency, rat, testis.

J. Vet. Med. Sci. 61(7): 755-760, 1999

Carbendazim (methyl 2-benzimidazole carbamate; MBC), a metabolite of the widely-used fungicide benomyl, is a microtubule disruptor $[3,10]$. These agents are environmental chemicals that are known to be toxic to mammalian reproductive organs [10,23]. Studies on their effects on testes have shown that they cause a sloughing of immature spermatids from the seminiferous epithelium by disrupting Sertoli cell microtubules within a few hours after oral exposure [7, 14, 16, 19]. When sloughed materials flow downstream in the excurrent ducts of the testis, they often occlude the efferent ductules (EFDs) and cause longterm effects such as severe inflammation and fibrosis [7, $16,17]$.

The EFDs of the testis are a series of ductules that function as a vital link that conducts sperm from the rete testis to the epididymis $[5,9,21]$. In addition, the seminiferous tubule fluid is actively absorbed by the nonciliated epithelial cells lining the EFDs [2, 6, 8, 11, 24]. Thus, when the EFDs are highly occluded with sloughed materials after treatment with benomyl or MBC, seminiferous tubule fluid accumulates in the testis and the fluid pressure builds up, eventually leading to testicular atrophy [12]. Carter et al. [1] reported that half of all MBC-treated rats were infertile and that their testes had atrophied completely. However, they also described in the same report that other rats that had been treated similarly were fertile, and that their testes contained normal and

* Correspondence to: Nakai, M., Department of Veterinary Anatomy, Faculty of Agriculture, Miyazaki University, Miyazaki 889-2192, Japan. atrophic seminiferous tubules at various frequencies.

The mechanism responsible for these differences in testicular damage has not been clarified, but the available data suggest that whether or not the animals are able to survive long-term effects of MBC depends largely on EFD patency. To test this hypothesis, we examined the relationship between the number of patent EFDs and testicular damage after a single dose of MBC.

\section{MATERIALS AND METHODS}

Male Sprague-Dawley rats (90-100 days old) were used in the present study. They were allowed free access to rodent chow and water throughout the experimental periods. Carbendazim (a gift from Dr. Rex Hess, University of Illinois, U. S. A.) was suspended in corn oil and administered to the animals by a single gavage at a dose of $100 \mathrm{mg} / \mathrm{kg}$. Five or six animals were assigned to each posttreatment interval $(8,16,32$ and 70 days). As controls, six rats were given the corn oil vehicle only; three were used at 8 days and three at 70 days after treatment.

At each interval, the animals were perfused with Bouin's solution using a vascular perfusion technique under deep anesthesia with pentobarbital, and the testes and epididymides were excised. The testes were weighed and all tissues were processed for paraffin embedding. Testicular sections were cut at a thickness of $4 \mu \mathrm{m}$, and stained with periodic acid-Schiff reagent, followed by nuclear staining with hematoxylin. Longitudinal sections of the caput epididymides containing EFDs were cut serially, and every fifth section was collected. The sections were 
stained with hematoxylin and eosin.

The number of patent EFDs was determined in each epididymis, and each testis was classified into one of the following groups: those with intact (no occluded) EFDs, those with partially patent EFDs, or those with totally occluded (no patent) EFDs. The testes with partially patent EFDs were further divided into three groups according to the number of patent EFDs (1, 2 or 3). In each testicular section, randomly selected 100 seminiferous tubules were examined for the presence of histopathological alterations, and classified into three categories: normal, degenerative (tubules with binucleate spermatids [15], spermatids with enlarged nuclei [15], chromatin margination of the germ cell nuclei, multinucleate giant cells, missing germ cells and/or vacuolization of the seminiferous epithelium) or atrophic (tubules containing Sertoli cells and a few spermatogonia [1]).

Testicular weights were compared using Student's $t$ test. Differences were considered significant at $p<0.05$.

\section{RESULTS}

Testis weight: The mean weight of the testes with partially occluded EFDs was significantly higher compared with that of the control (Table 1). When the values were assigned according to the number of patent EFDs, testes with fewer patent EFDs were heavier than those with more patent EFDs (Table 2). The mean weight of the testes with totally occluded EFDs was significantly lower (Table 1).

Histopathology of the testis and EFD: Although degenerative changes including necrosis of the germ cells, binucleate spermatids, spermatids with enlarged nuclei, and vacuolization of the seminiferous epithelium, were rarely observed, most seminiferous tubules of the control testes were normal histologically (Fig. 1). No abnormality was seen in the EFDs of the control animals (Fig. 2).

The abnormalities of the EFDs after exposure to MBC were similar to those reported previously [17]. Briefly, they were occluded with the sloughed materials from the seminiferous tubules, and severely inflamed at day 8 .

Table 1. Mean weights of testes showing different patencies of the efferent ductules (EFDs) after treatment with carbendazim $(\mathrm{g} \pm \mathrm{SD})$

\begin{tabular}{cccc}
\hline Control testes & $\begin{array}{c}\text { Testes with } \\
\text { intact EFDs }\end{array}$ & $\begin{array}{c}\text { Testes with partially } \\
\text { patent EFDs }\end{array}$ & $\begin{array}{c}\text { Testes with totally } \\
\text { occulded EFDs }\end{array}$ \\
\hline $\begin{array}{c}1.73 \pm 0.11 \\
\left(\mathrm{n}^{\dagger}=12\right)\end{array}$ & $\begin{array}{c}1.69 \pm 0.10 \\
\left(\mathrm{n}^{\dagger}=21\right)\end{array}$ & $\begin{array}{c}1.97 \pm 0.31^{*} \\
\left(\mathrm{n}^{\dagger}=20\right)\end{array}$ & $\begin{array}{c}1.05 \pm 0.16^{* *} \\
\left(\mathrm{n}^{\dagger}=3\right)\end{array}$ \\
\hline
\end{tabular}

$\dagger$ Total number of testes from day 8 to day 70 post-treatment.

* Significantly higher compared with the control $(p<0.05)$.

** Significantly lower compared with the control $(p<0.01)$.

Table 2. Mean weights of testes assigned by the number of patent efferent ductules (EFDs) after treatment with carbendazim $(\mathrm{g} \pm$ SD)

\begin{tabular}{cccc}
\hline Control & $\begin{array}{c}\text { Testes with 1 } \\
\text { patient EFD }\end{array}$ & $\begin{array}{c}\text { Testes with 2 } \\
\text { patent EFDs }\end{array}$ & $\begin{array}{c}\text { Testes with 3 } \\
\text { patent EFDs }\end{array}$ \\
\hline $\begin{array}{c}1.73 \pm 0.11 \\
\left(\mathrm{n}^{\dagger}=12\right)\end{array}$ & $\begin{array}{c}2.26 \pm 0.22^{*} \\
\left(\mathrm{n}^{\dagger}=8\right)\end{array}$ & $\begin{array}{c}1.84 \pm 0.15 \\
\left(\mathrm{n}^{\dagger}=8\right)\end{array}$ & $\begin{array}{c}1.66 \pm 0.24 \\
\left(\mathrm{n}^{\dagger}=4\right)\end{array}$ \\
\hline
\end{tabular}

† Total number of testes from day 8 to day 70 post-treatment. * Significantly higher compared with the control $(p<0.01)$.
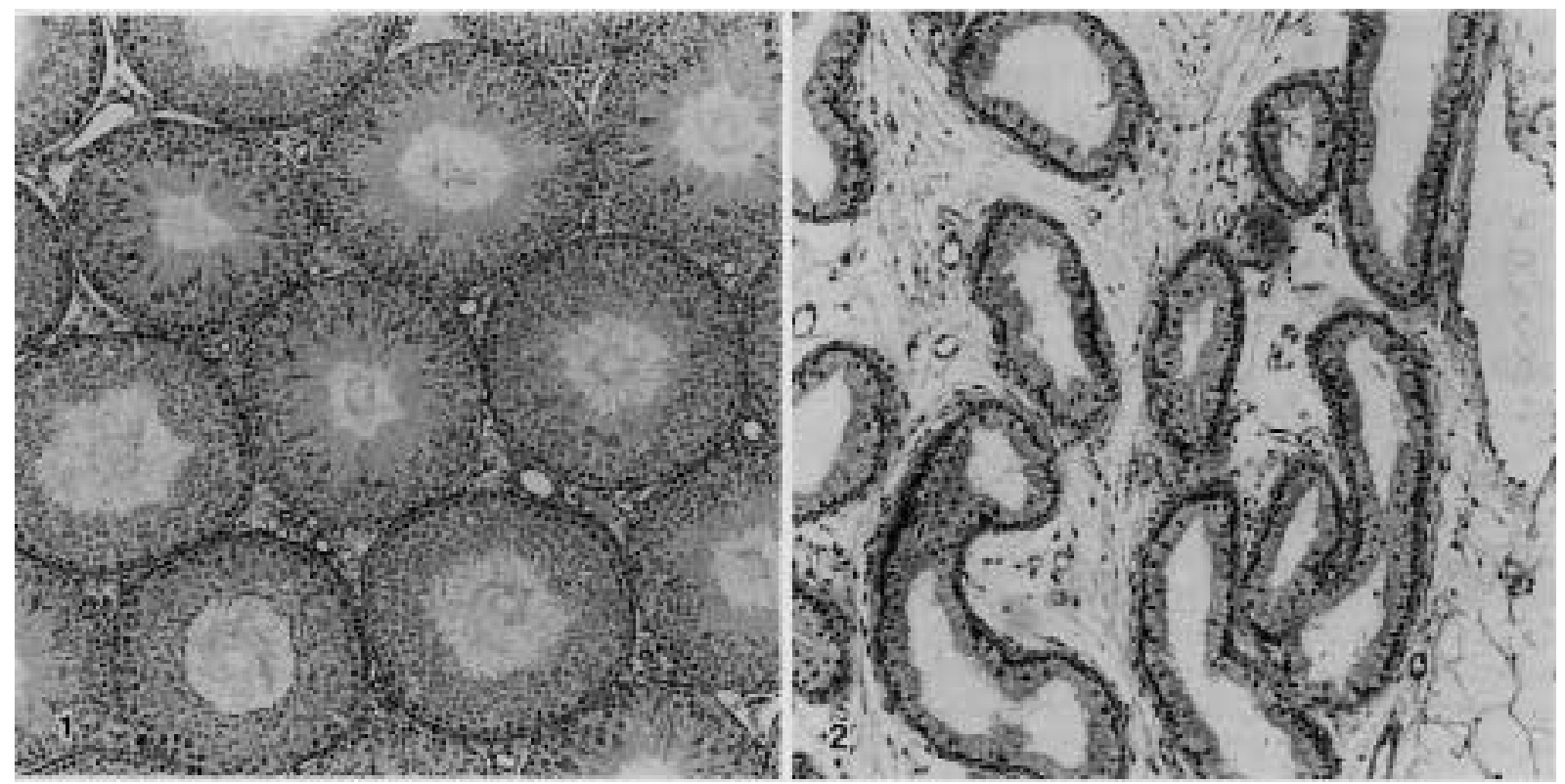

Fig. 1. Testis of the control animal showing normal structure of the seminiferous tubules. Periodic acid-Schiff and hematoxylin. $\times 88$.

Fig. 2. Efferent ductules of the control animal. No occlusion is observed. Hematoxylin and eosin. $\times 88$. 
Table 3. Frequencies (mean \%) of normal (Nor), degenerative (Deg) and atrophic (Atr) seminiferous tubules in testes with different numbers of patent efferent ductules (EFDs) after treatment with carbendazim

\begin{tabular}{|c|c|c|c|c|c|c|c|c|c|c|c|c|c|c|c|c|c|c|c|c|c|c|c|c|}
\hline \multirow[t]{2}{*}{$\begin{array}{l}\text { Interval } \\
\text { (days) }\end{array}$} & \multicolumn{4}{|c|}{ Control } & \multicolumn{4}{|c|}{$\begin{array}{l}\text { Testes with } \\
\text { intact EFDs }\end{array}$} & \multicolumn{4}{|c|}{$\begin{array}{l}\text { Testes with } \\
3 \text { patent EFDs }\end{array}$} & \multicolumn{4}{|c|}{$\begin{array}{c}\text { Testes with } \\
2 \text { patent EFDs }\end{array}$} & \multicolumn{4}{|c|}{$\begin{array}{c}\text { Testes with } \\
1 \text { patent EFD }\end{array}$} & \multicolumn{4}{|c|}{$\begin{array}{l}\text { Testes with totally } \\
\text { occluded EFDs }\end{array}$} \\
\hline & $\mathrm{n}$ & Nor & Deg & Atr & $\mathrm{n}$ & Nor & Deg & Atr & $\mathrm{n}$ & Nor & Deg & Atr & $\mathrm{n}$ & Nor & Deg & Atr & $\mathrm{n}$ & Nor & Deg & Atr & $\mathrm{n}$ & Nor & Deg & Atr \\
\hline 8 & & & & & 6 & 95.8 & 4.2 & 0.0 & 1 & 84.0 & 16.0 & 0.0 & 2 & 71.0 & 29.0 & 0.0 & 1 & 27.0 & 67.0 & 6.0 & 0 & & & \\
\hline 16 & 12 & 98.3 & 1.7 & 0.0 & 1 & 90.0 & 10.0 & 0.0 & 3 & 92.0 & 8.0 & 0.0 & 0 & & & & 4 & 44.3 & 46.7 & 9.0 & 2 & 13.0 & 26.0 & 61.0 \\
\hline 32 & & & & & 7 & 93.7 & 603 & 0.0 & 0 & & & & 3 & 92.3 & 7.7 & 0.0 & 2 & 55.5 & 44.5 & 0.0 & 0 & & & \\
\hline 70 & & & & & 7 & 97.3 & 2.7 & 0.0 & 0 & & & & 3 & 89.7 & 9.7 & 0.7 & 1 & 71.0 & 29.0 & 0.0 & 1 & 10.0 & 3.0 & 87.0 \\
\hline
\end{tabular}

Thereafter the lumina of these ductules were often replaced with fibrous connective tissue.

Of 10 testes collected eight days after treatment, six had intact EFDs, four had partially patent EFDs, and none had totally occluded EFDs (Table 3). Although abnormalities of germ cells such as missing round and elongated spermatids, and spermatids with enlarged nuclei were observed in the testes with intact EFDs, they were few in number. No atrophic seminiferous tubule occurred in these testes. The testes with partially patent EFDs contained abnormal seminiferous tubules at various frequencies, depending on the degree of patency (Table 3). In the testes with two and three patent EFDs, normal seminiferous tubules were the most numerous, followed by tubules with degenerative alterations; no atrophic tubules were observed (Figs. 3, 4). In the testis with one patent EFD, however, seminiferous tubules showing degenerative alterations were the most numerous, then the normal tubules, and the atrophic tubules were the least numerous. Seminiferous tubule swelling was observed in one testis with two patent EFDs and one testis with one patent EFD, although the cells of the seminiferous epithelium were normal.

Of the 10 testes collected at day 16, one had intact EFDs, seven had partially patent EFDs, and two had totally occluded EFDs (Table 3). In the testes with intact and three patent EFDs, $90 \%$ or more seminiferous tubules were normal. In the testes with one patent EFD, degenerative and normal seminiferous tubules were observed at approximately the same frequencies (Fig. 5). Atrophic seminiferous tubules were the most numerous in the testes with totally occluded EFDs. One of the three testes with three patent EFDs and three of the four testes with one patent EFD contained swollen seminiferous tubules.

Of the 12 testes collected at day 32, seven had intact EFDs, five had partially patent EFDs, and none had totally occluded EFDs (Table 3). Over $90 \%$ of the seminiferous tubules were normal in the testes with intact and two patent EFDs. In the testes with one patent EFD, more than $50 \%$ of the seminiferous tubules were normal, but degenerative seminiferous tubules were observed in approximately $45 \%$. Seminiferous tubule swelling was observed in both testes with one patent EFD.

Of the 12 testes collected at day 70 , seven had intact EFDs, four had partially patent EFDs, and one had totally occluded EFDs (Table 3). In the testes with intact and two patent EFDs, approximately $90 \%$ or more seminiferous tubules were normal. In the testis with one patent EFD, approximately $70 \%$ of the seminiferous tubules had normal except that they were swollen. On the other hand, atrophic seminiferous tubules were predominant in the testis with totally occluded EFDs (Fig. 6).

\section{DISCUSSION}

For all post-treatment intervals examined in the present study, most seminiferous tubules were histologically normal in testes with intact EFDs. When the histopathological changes in the testes with partially patent and totally occluded EFDs were assessed according to the degree of patency, the more EFDs remained patent, the more seminiferous tubules were normal. For example, normal seminiferous tubules were observed only in $10-13 \%$ in the testes with totally occluded EFDs, whereas they were observed much more often in the testes with three patent EFDs. These results clearly demonstrate that whether or not the testis is able to survive the long-term deleterious effects of MBC depends largely on the number of patent EFDs, and indicate that most seminiferous tubules can maintain their normal structure when two or three EFDs remain patent.

Occlusion of the EFDs results in the accumulation of fluid in the testis, which causes seminiferous tubule swelling and then testicular atrophy [7, 16, 22]. In the present study, the testes with one patent EFD were swollen and contained degenerative and atrophic seminiferous tubules. This is attributable to the continued production of the seminiferous tubule fluid, at least until day 70 after treatment, and the restricted outflow of the fluid due to the reduced patency of the EFDs. Nevertheless, the testes contained seminiferous tubules showing normal germ cell associations, and these seminiferous tubules increased progressively in number as the post-treatment intervals increased, and reached $71 \%$ at day 70 . Therefore, although the sperm production in these testes was probably reduced accordingly, males with one patent EFD can be fertile. This is supported by the fact that laboratory species such as rat produce many more sperm than are necessary for fertility and at least $90 \%$ of spermatogenesis must be damaged to affect the number of progeny produced [20]. However, it is possible that testes with one patent EFD could exhibit total or partial atrophy if the inflow of fluid exceeded the outflow from the EFDs some time after day 70 . 


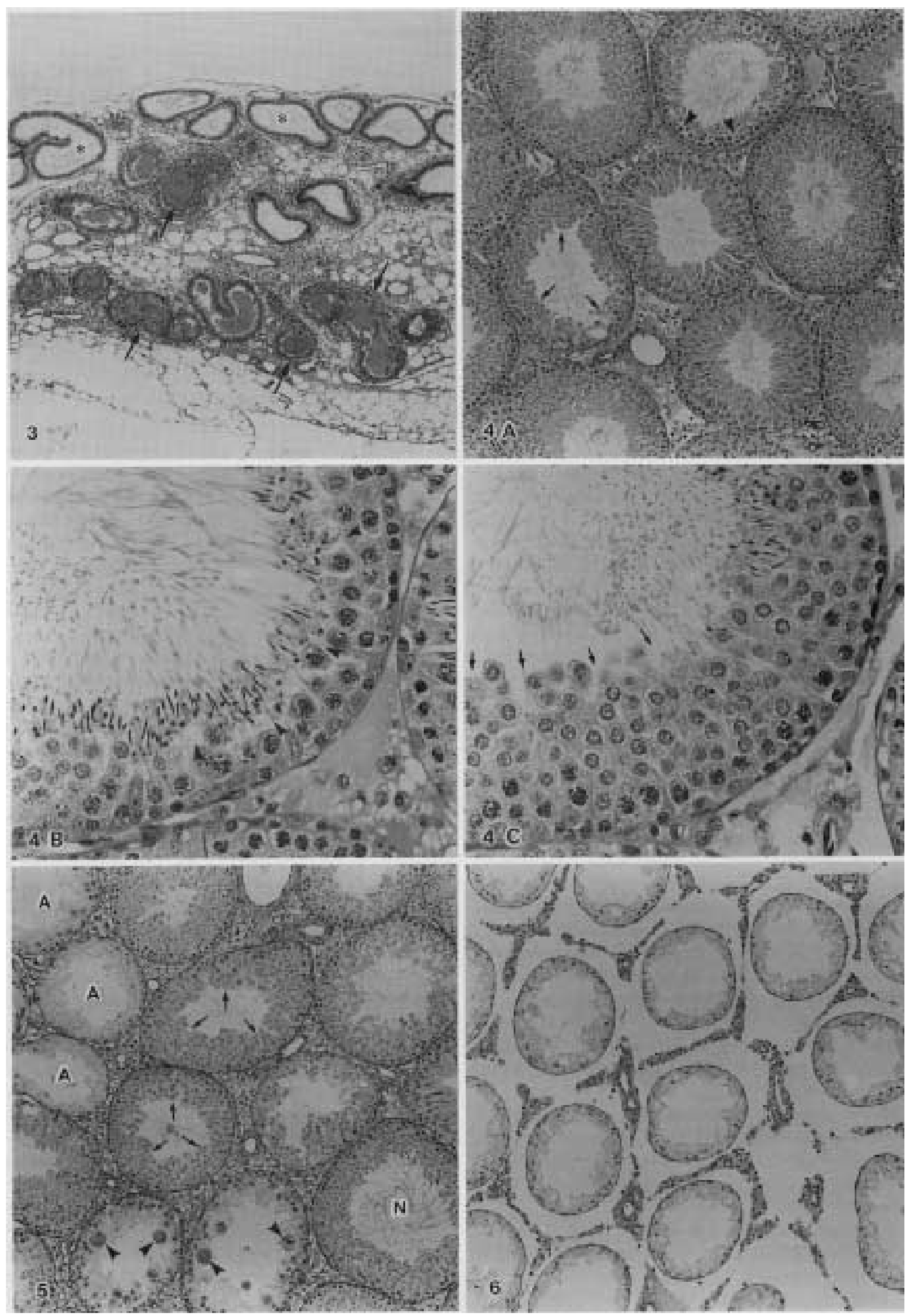


In the present study, normal seminiferous tubules were initially less abundant and then gradually became more abundant as the post-treatment interval increased, regardless of the degree of patency. Specific germ cell types are susceptible to MBC, and these cells may show abnormal development after treatment $[15,18]$. Alternatively, they may fail to survive the initial effects of $\mathrm{MBC}$ and be missing at earlier follow-up intervals [15]. These facts may account for the early temporal increase of seminiferous tubules that had abnormal germ cells. However, MBC is rapidly excreted and does not accumulate in animal tissues [4, 10, 13]. Therefore, it is likely that germ cells that are not susceptible to MBC develop normally, reconstruct the seminiferous epithelium, and contribute to the greater number of normal seminiferous tubules after a longer follow-up interval unless the EFDs are severely occluded. On the other hand, atrophic seminiferous tubules were predominant in the testes with totally occluded EFDs. Although these testes contained a few normal seminiferous tubules, EFDs do not regain patency once they are involved in fibrosis, as discussed elsewhere [17]. Thus, it is unlikely that the rats with totally occluded EFDs are fertile. The absence of sperm in the epididymal ducts of these animals (data not shown) supports this idea.

In conclusion, the present study has shown that EFD patency is crucial for the maintenance of normal testicular structures after treatment with MBC. Greater attention must therefore be paid to alterations in the EFDs when chemical effects on the testis are assessed.

\section{REFERENCES}

1. Carter, S. D., Hess, R. A. and Laskey, J. W. 1987. The fungicide methyl 2-benzimidazole carbamate causes infertility in male Sprague-Dawley rats. Biol. Reprod. 37: 709-717.

2. Crabo, B. 1965. Studies on the composition of epididymal content in bulls and boars. Acta Vet. Scand. (Suppl.) 5: 1-94.

3. Davidse, L. C. and Flach, W. 1997. Differential binding of methyl benzimidazole-2-yl carbamate to fungal tubulin as a mechanism of resistance to this antimitotic agent in mutant strains of Aspergillus nidulans. J. Cell Biol. 72: 174-193.

4. Gardiner, J. A., Kirkland, J. J., Klopping, H. L. and Sherman, H. 1974. Fate of benomyl in animals. J. Agric. Food Chem. 22: 419-427.

5. Guttroff, R. F., Cooke, P. S. and Hess, R. A. 1992. Blindending tubules and branching patterns of the rat ductuli efferentes. Anat. Rec. 232: 423-431.
6. Hermo, L. and Morales, C. 1984. Endocytosis in nonciliated epithelial cells of the ductuli efferentes in the rat. Am. J. Anat. 171: 59-74.

7. Hess, R. A., Moore, B. J., Forrer, J., Linder, R. E. and AbuelAtta, A. A. 1991. The fungicide benomyl (methyl 1(butylcarbamoyl)-2-benzimidazole carbamate) causes testicular dysfunction by inducing the sloughing of germ cells and occlusion of efferent ductules. Fund. Appl. Toxicol. 17: 733745.

8. Illio, K. Y. and Hess, R. A. 1992. Localization and activity of the $\mathrm{Na}^{+}, \mathrm{K}^{+}$- ATPase in the ductuli efferentes of the rat. Anat. Rec. 234: 190-200.

9. Illio, K. Y. and Hess, R. A. 1994. Structure and function of the ductuli efferentes: a review. Microsco. Res. Tech. 29: 432-467.

10. International programme on chemical safety. 1993. Environmental Health Criteria 149, Carbendazim, World Health Organization, Geneva, Switzerland.

11. Jones, R. C. and Jurd, K. M. 1987. Structural differentiation and fluid reabsorption in the ductuli efferentes testis of the rat. Austr. J. Biol. Sci. 40: 79-90.

12. Klinefelter, G. R. and Hess, R. A. 1998. Toxicology of the male excurrent ducts and accessory sex glands. pp. 553-591. In: Reproductive and Developmental Toxicology (Korach, K. S. ed.), Marcel Dekker. Inc., New York.

13. Krechniak, J. and Klosowska, B. 1986. The rate of ${ }^{14} \mathrm{C}-$ carbendazim in rat. Xenobiotica 16: 809-815.

14. Nakai, M. and Hess, R. A. 1994. Morphological changes in the rat Sertoli cell induced by the microtubule poison carbendazim. Tissue Cell 26: 917-927.

15. Nakai, M. and Hess, R. A. 1997. Effects of carbendazim (methyl 2-benzimidazole carbamate; MBC) on meiotic spermatocytes and the subsequent spermiogenesis in the rat testis. Anat. Rec. 247: 379-387.

16. Nakai, M., Hess, R. A., Moore, B. J., Guttroff, R. F., Strader, L. F. and Linder, R. E. 1992. Acute and long-term effects of a single dose of fungicide carbendazim (methyl 2 benzimidazole carbamate) on the male reproductive system in the rat. $J$. Androl. 13:507-518.

17. Nakai, M., Moore, B. J. and Hess, R. A. 1993. Epithelial reorganization and irregular growth following carbendaziminduced injury of the efferent ductules of the rat testis. Anat. Rec. 235: 51-60.

18. Nakai, M., Toshimori, K., Yoshinaga, K., Nasu, T. and Hess, R. A. 1998. Carbendazim-induced abnormal development of the acrosome during early phases of spermiogenesis in the rat testis. Cell Tissues Res. 294: 15-152.

19. Parvinen, M. and Kormano, M. 1974. Early effects of antispermatogenic benzimidazole derivatives U32.422E and U32.104 on the seminiferous epithelium of the rat. Andrologia

Fig. 3. Occlusions of the efferent ductules eight days after treatment with carbendazim. The lumen of the ductules are filled with sloughed materials (arrows). The patent ductules (asterisks) are not involved in inflammation, but are expanded. Hematoxylin and eosin. $\times 35$.

Fig. 4. Testis with three patent efferent ductules eight days after treatment with carbendazim. Most seminiferous tubules are normal histologically (A), but step 7 (arrowheads) and 19 (arrows) spermatids are missing in a few Stage VII tubules. Higher magnifications of these abnormalities are indicated in B (arrowheads) and C (arrows), respectively. Periodic acid-Schiff and hematoxylin. A: $\times 88, \mathrm{~B}$ and C: $\times 350$.

Fig. 5. Testis with one patent efferent ductule 16 days after treatment with carbendazim. Seminiferous tubules with various abnormalities are seen. A: atrophic tubules, Arrows: missing of elongate spermatids, Arrowheads: multinucleate giant cells, N: normal tubule. Periodic acid-Schiff and hematoxylin. $\times 88$.

Fig. 6. Testis with totally occluded efferent ductule 70 days after treatment with carbendazim. Most seminiferous tubules are atrophic. Periodic acid-Schiff and hematoxylin. $\times 88$. 
6: $245-253$.

20. Russell, L. D., Ettlin, R. A., Sinha Hikim, A. P. and Clegg, E. D. 1990. Histological and Histopathological Evaluation of the Testis. Cache River Press, Clearwater, Florida.

21. Setchell, B. P., Maddocks, S. and Brooks, D. E. 1994. Anatomy, vasculature, innervation, and fluids of the male reproductive tract. pp. 1063-1175. In: The Physiology of Reproduction, 2nd ed. (Knobil, E. and Neill, J. D. eds.), Raven Press, New York.

22. Smith, G. 1962. The effects of ligation of the vasa efferentia and vasectomy on testicular function in the adult rat. $J$. Endocrinol. 23: 385-399.
23. Toppari, J., Larsen, J. C., Christiansen, P., Giwercman, A. Grandjean, P., Guillette Jr, L. J., Jegou, B., Jensen, T. K., Jouannet, P., Keiding, N., Leffers, H., McLachlan, J. A., Meyer, O., Müler, J., Meyts, E. R., Scheike, T., Sharpe, R., Sumpter, J. and Skakkebæk, N. E. 1996. Male reproductive health and environmental xenoestrogens. Environ. Health Perspect. (Suppl.) 4: 741-803.

24. Veeramachaneni, D. N. R., Aman, R. P. and Palmer, J. 1990. Proteins in luminal fluid of the ram excurrent ducts: Changes in composition and evidence for differential endocytosis. $J$. Androl. 11: 140-154. 